\title{
Energy Harvesting from Rotating Motion of In-Pipe Robot Cleaning Device
}

\author{
A. S. Z. Abidin 1, , T. B. Sawing1, S. Mohamaddan', H. H. A. Halim², \\ J. Annisa ${ }^{1}$, R. Muslimen ${ }^{1}$, M. F. Ashari ${ }^{1}$ and M. S. Jamaludin ${ }^{1}$ \\ ${ }^{1}$ Department of Mechanical and Manufacturing Engineering, Faculty of Engineering, \\ Universiti Malaysia Sarawak, 94300 Kota Samarahan, Sarawak, Malaysia \\ *Email: zaasakura@unimas.my \\ Phone: +6082583306; Fax: +6082583410 \\ ${ }^{2}$ Department of Electrical and Electronic Engineering, Faculty of Engineering, \\ Universiti Malaysia Sarawak, 94300 Kota Samarahan, Sarawak, Malaysia
}

\begin{abstract}
In-pipe robot (IPR) needs a continuous and constant power supply for its operation. This research is a continuation from the previous IPR: D200 for cleaning operation. The objective of this research is to study the possibility of harvesting electrical energy from IPR and how much electrical output can be generated from the proposed solution. The concept is to re-use kinetic energy from high speed rotation of the IPR cleaning device to be converted into electrical energy which can be used to recharge the main battery. Two types of circuits have been developed namely unregulated charging circuit and regulated charging circuit. Both developed circuits are simulated using Livewire software. The developed circuits are then validated using experiment to measure the output voltage. Simulation results show that the unregulated charging circuit can produce output voltage of $10.90 \mathrm{~V}$ while regulated charging circuit produces an output voltage of $5.47 \mathrm{~V}$. Experiments have confirmed that unregulated charging is able to produce higher voltage of $6.93 \mathrm{~V}$ as compared to regulated charging circuit. The experimental results are lower than simulation results due to power loss during power transmission of the actual circuits. In the meantime, the unregulated charging circuit produced inconsistent output compared to the regulated charging circuit. Therefore, the regulated charging circuit will be considered for the IPR: D200 applications as well as other similar applications.
\end{abstract}

Keywords: Power regeneration; kinetic energy; electrical energy; in-pipe robot.

\section{INTRODUCTION}

Nowadays, application of robots is widely used to assist humans in handling hazardous and difficult tasks. Application of robots in pipeline maintenance and inspection has been established for many years and become more popular due to the nature of inaccessible pipeline and hazardous environment [1]. IPR for cleaning operation of a sewerage pipeline has been developed. A set of nylon cables were rotated by a high speed motor for cleaning operation of the IPR [2].

All movements and control of the IPR is driven by batteries. Battery is a wireless power and an appropriate power source for in-pipe robot in order to improve its mobility. However, power from the battery is not infinite. The battery must be charged regularly to ensure sufficient level of power for operation until it reaches the next manhole (exit). The weight of the battery is the heaviest component compared to the total weight of the IPR [1]. Thus, the battery itself becomes a burden to the IPR as more power is consumed to 
move the heavy load. There is a tradeoff between the number of battery for longer power supply and higher power needed to carry the heavy load of the batteries.

Intermittent power source of the IPR has limited the robot performance. Considering the actual length of pipeline system can reach thousands of kilometers, there is need to develop a system that can extend the batteries life for longer operation. The geometrical features, type of locomotion system, controlling system, functions and operations of the robot must be considered before a potential power regeneration system can be developed [3]. Therefore, the number of battery use must be minimised and efficient self-generated energy is needed to ensure continuous power supply of the device.

Mechanical and rotor powered systems are well established and widely used [4][5][6]. Many wireless robots use conventional power source which is battery to operate $[1,2,6]$. Recently, a non-conventional power source started to get attention from researchers. Pneumatic battery that applies Hydrogen Peroxide as source of power has been introduced in a soft mobile robot [7]. However, pneumatic battery has not been established yet and at the same time there is concern on the chemical reaction of Hydrogen Peroxide byproducts into the sewerage system environment. Outdoor robots or devices may use solar or wind power as source of green energy. Besides high capital cost investment, the energy efficiency also varies being dependent on geographical factors, seasons and also location of the intended application [6], [8], [9]. The IPR is designed for closed in the pipe sewerage system; there is restriction of sunlight irradiation to reach the device and no wind access too. Selection of an appropriate power source is important as the selection affects the power regeneration system development and performance of the IPR. The system must be efficient, practical and lightweight. In addition, the idea must be compatible with many small electronic appliances available in the market.

To operate the DC motor, an independent power source such as battery is needed especially when the robot is working wireless. This project focuses on the method to extend performance of the battery by regenerating the power used by the IPR. The IPR is equipped with a high speed DC motor that rotates the nylon cables to create cutting effect for the IPR cleaning operation $[1,2]$. As the IPR cleaning device rotates at high speed during its operation, the rotation is potentially able to convert magnetic flux through a loop into induced current. This project intends to harvest electrical energy from available sources of the existing IPR. The concept of a bicycle dynamo that converts the moving wheels to produce direct current to generate power for the light is significant to this research. Dynamo applies Faraday's Law, where the magnetic field resulted from rotation of coil inside a conductor such as permanent magnet will eventually induce voltage that generates electricity [11].

The aim of this research is to extend the longevity of the IPR through efficient self-powered generation. Basically, this project applies the concept of converting mechanical energy to electrical energy. The paper focuses on feasibility of a standalone generator connected to a dual-rotor DC motor of the IPR while performing cleaning operation. The power generated has to be sufficient for the IPR to operate in the pipeline.

\section{METHODOLOGY}

This research begins with gathering of information of related topics followed by a concept development. Three different circuits have been developed from the generated concept. The circuits are then simulated using Livewire software. Finally, the developed circuits are validated to find the most optimum circuit to be implemented in the IPR. 


\section{Concept Development}

The concept of energy harvesting has been developed based on the information gathered. The idea is to use kinetic energy from the rotating shaft of the cleaning device of the DC motor to rotate the dynamo or generator to produce electricity. The electricity generated can be used to charge up the rechargeable battery used by the IPR. Figure 1 shows the schematic design of the energy harvesting concept. A dual-shaft DC motor has been selected to rotate the cleaning device while the other side of the shaft is used to drive a gear system as marked by the dotted circle. The forces transmitted between the meshing gears are used to supply torsional moment to rotate the generator.

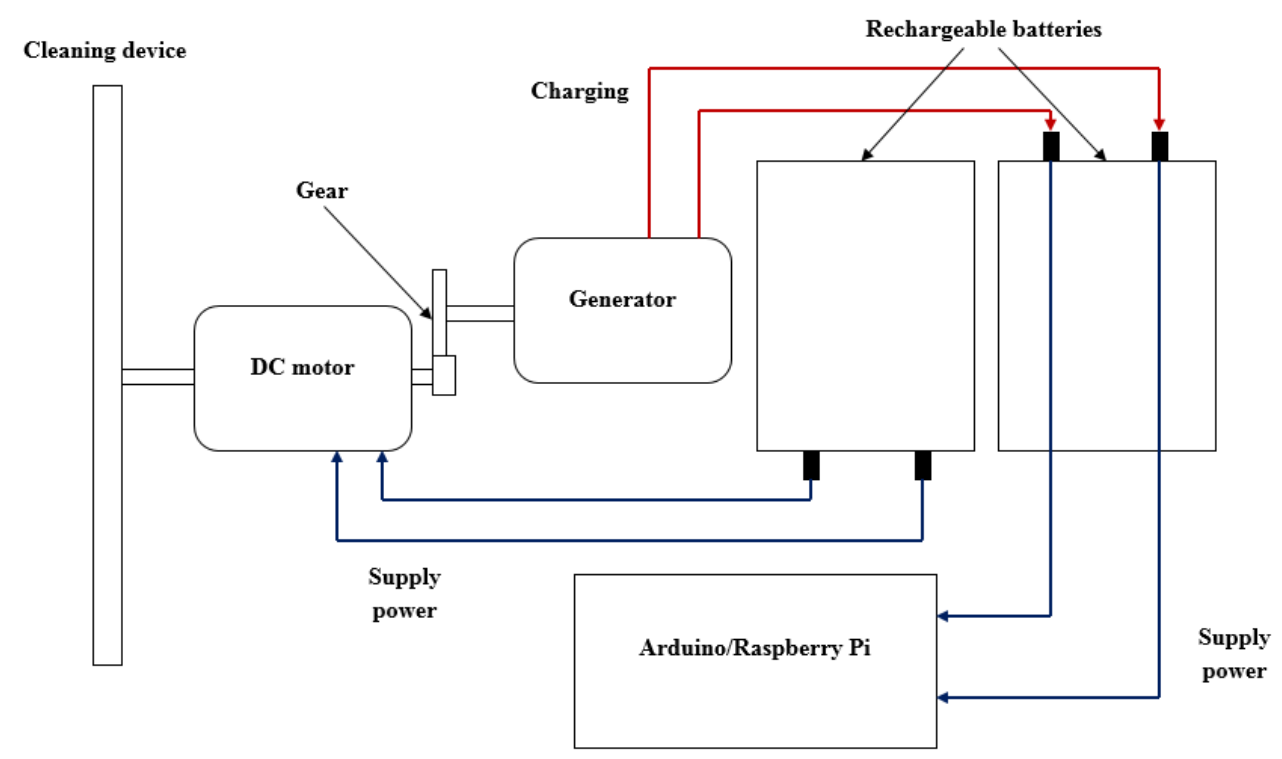

Figure 1. Energy harvesting concept

\section{Development of Power Regeneration System}

A gear system has been introduced to ensure efficient power transmission. The role of the gear system is to transmit power from the cleaning device motor to the dynamo and at the same time functions as controller to make sure a certain level of revolutions per minute (rpm) is achieved to meet the generator specifications. As the two gears are meshed, the gears pitch circles roll on one another without slipping at certain pitch line velocity. The two meshed gears have different pitch radii input and output as $r_{1}$ and $r_{2}$ (inch) and angular velocities as $\omega_{1}$ and $\omega_{2}(\mathrm{rpm})$. The pitch line velocity, $\mathrm{V}$ is defined as the distance covered in unit time as shown in Eq. (1) [12].

$\mathrm{V}=\omega_{1} \mathrm{r}_{1}=\omega_{2} \mathrm{r}_{2}$

By knowing the targeted angular velocities of the input and output speeds, the ratio of the pitch radii can be determined for the gears selection. Gear ratio is defined as the input speed, $\Phi_{1}$ relative to the output speed, $\oplus_{2}$ as shown in Eq. (1) and becoming Eq. (2). Based on Eq. (2), the number of gear teeth, $\mathrm{N}$ can be specified.

Gear ratio $=\omega_{1} / \omega_{2}=\mathrm{N}_{2} / \mathrm{N}_{1}$ 
Ohm's Law is the fundamental concept for generating electricity. Referring to Ohm's Law, voltage $(\mathrm{V})$ equals to the product of currents, I (Ampere) and resistance, $\mathrm{R}(\mathrm{Ohms})$ as shown in Eq. (3) [13].

$\mathrm{V}=\mathrm{I} \times \mathrm{R}$

\section{Power transmission}

The dual-shaft DC motor is introduced to replace the initial IPR DC motor. The dualshaft DC motor enables dual functions; one shaft for cleaning device and another shaft to be connected to the generator. The gear is used to transmit power from the DC motor to the generator. The cleaning device requires high speed rotation, while the generator has lower input speed limit. Therefore, the gear system is necessary to reduce the speed. According to dual-shaft motor specifications the speed is $11,500 \mathrm{rpm}$. Considering $20 \%$ loss due to the cleaning device load the speed becomes, $\Phi_{1}=9,200 \mathrm{rpm}$. Meanwhile, the maximum speed limit of the generator is, $\omega_{2}=7,360 \mathrm{rpm}$. Substituting the speed values into Eq. (2) to determine the gear ratio, the following equation is obtained.

Gear ratio $=\omega_{1} / \omega_{2}$

The number of gear teeth can be determined from the gear ratio. The number of driver gear teeth, $\mathrm{N}_{1}$ and the number of teeth for driven gear, $\mathrm{N}_{2}$ of the generator must tally with each other. Therefore, the speed from the DC motor has been reduced to 7,360 rpm which is compatible with the maximum speed received by the generator.

\section{Electronics devices}

Table 1 shows the summary of electronic device specifications for the proposed energy harvesting system. The volts-to-rpm ratio is one of the most important factors in choosing the right motor for the generator. It is defined as the volts needed to rotate the motor at a given revolution per minute as shown in Eq. (5). The analysis to determine output from DC motor acting as generator is as shown.

V-to-rpm ratio $=\mathrm{V} / \mathrm{rpm}$

The maximum speed, $v$ that can be received by the generator is 7,360 rpm. The maximum voltage, $\mathrm{V}$ that can be produced by the generator is shown in Eq. (6).

$\mathrm{V}_{\max }=v_{\max } \times \mathrm{V} / \mathrm{rpm}$

Assuming the efficiency, $\eta$ of the DC motor operating as generator is $80 \%$, actual voltage produced by the generator is shown in Eq. (7). The rechargeable battery used in power regeneration system is lithium polymer type with rated voltage of $3.7 \mathrm{~V}$ (maximum $4.2 \mathrm{~V}$ ) and capacity of $1300 \mathrm{mAh}$. The battery will use a charge rate at $\mathrm{C} / 5$ as shown in Eq. (8) to be safe which means it will take up to 5 hours to get fully charged. Hence, the charge current will be $260 \mathrm{mAh}$ for 5 hours.

$\mathrm{V}=\mathrm{V}_{\max } * \eta$ 
Charge rate $=$ Battery capacity $/$ time

A resistor is needed to keep the current at an acceptable rate for battery charging. Based on Eq. (2), a suitable value for resistor can be determined. The voltage based on the battery specification used in the charging circuit which is $4.2 \mathrm{~V}$, and the current from Eq. (8) are then substituted in Eq. (2) to determine the resistor as in Eq. (9).

$\mathrm{R}=\mathrm{V} / \mathrm{I}_{\mathrm{c}}$

Hence, the value of the resistor needed for battery charging is $16.15 \Omega$. Since there is no resistor component with the calculated value, an available resistor with $10 \Omega$ is chosen. Consequently, a new charging current must be determined as in Eq. (9). A new charging current will produce a charging rate of $\mathrm{C} / 3.1$. Therefore, the battery will get fully charged after 3.1 hours.

The diode to be used in the circuit is a 1N4007 type. A 1N4007 type diode has a peak repetitive reverse voltage value of $1,000 \mathrm{~V}$ which is highest among all other diodes of the same class [14]. The voltage regulator to be used in the circuit is a LM7085 type. A LM7085 type is used to regulate the output voltage to $5 \mathrm{~V}$ and deliver up to $15 \mathrm{~A}$ output current [15].

Table 1. Electronic device specifications.

\begin{tabular}{|c|c|c|}
\hline Component & Function & Specifications \\
\hline DC motor & As cleaning device & $\begin{array}{l}\text { Rated voltage: } 12 \mathrm{~V}, 15 \mathrm{~V} \max \\
11,500 \mathrm{rev} / \mathrm{min} \text { at } 12 \mathrm{~V} \\
\text { Dual shaft }\end{array}$ \\
\hline Generator & To generate electricity & $\begin{array}{l}\text { Rated voltage: } 12 \mathrm{~V} \\
6,500 \mathrm{rev} / \mathrm{min} \text { at } 12 \mathrm{~V}\end{array}$ \\
\hline $\begin{array}{l}\text { Rechargeable } \\
\text { battery }\end{array}$ & $\begin{array}{l}\text { To supply power to cleaning } \\
\text { device }\end{array}$ & $\begin{array}{l}\text { Rated voltage: } 11.1 \mathrm{~V}, 12.6 \mathrm{~V} \\
\max \\
\text { Capacity: } 2,200 \mathrm{mAh}\end{array}$ \\
\hline $\begin{array}{l}\text { Rechargeable } \\
\text { battery }\end{array}$ & $\begin{array}{l}\text { To supply power to micro- } \\
\text { controller or other actuators }\end{array}$ & $\begin{array}{l}\text { Rated voltage: } 3.7 \mathrm{~V}, 4.2 \mathrm{~V} \\
\max \\
\text { Capacity: } 1,300 \mathrm{mAh}\end{array}$ \\
\hline Resistor & $\begin{array}{l}\text { To control flow of current to } \\
\text { other components }\end{array}$ & $\begin{array}{l}\text { Rated resistance: } 10 \Omega \\
\text { Rated power: } 0.25 \mathrm{~W}\end{array}$ \\
\hline Diode & $\begin{array}{l}\text { To allow electric current to pass } \\
\text { in one direction, while blocking } \\
\text { current in the opposite direction }\end{array}$ & $\begin{array}{l}1 \mathrm{~N} 4007 \text { type } \\
\text { Peak reverse repetitive } \\
\text { voltage: } 1,000 \mathrm{~V}\end{array}$ \\
\hline $\begin{array}{l}\text { Voltage } \\
\text { regulator }\end{array}$ & $\begin{array}{l}\text { To maintain steady output of } \\
\text { volts in a circuit }\end{array}$ & $\begin{array}{l}\text { LM7805 type } \\
\text { Output voltage: } 5 \mathrm{~V} \\
\text { Output current: } 1.5 \mathrm{~A}\end{array}$ \\
\hline
\end{tabular}

\section{Electrical Circuit}

There are two electrical circuits developed for this system. One circuit is unregulated charging (refer to Figure 2) and another circuit is regulated charging (refer to Figure 3). The only difference between these two circuits is the regulated charging circuit is equipped with a voltage regulator. 


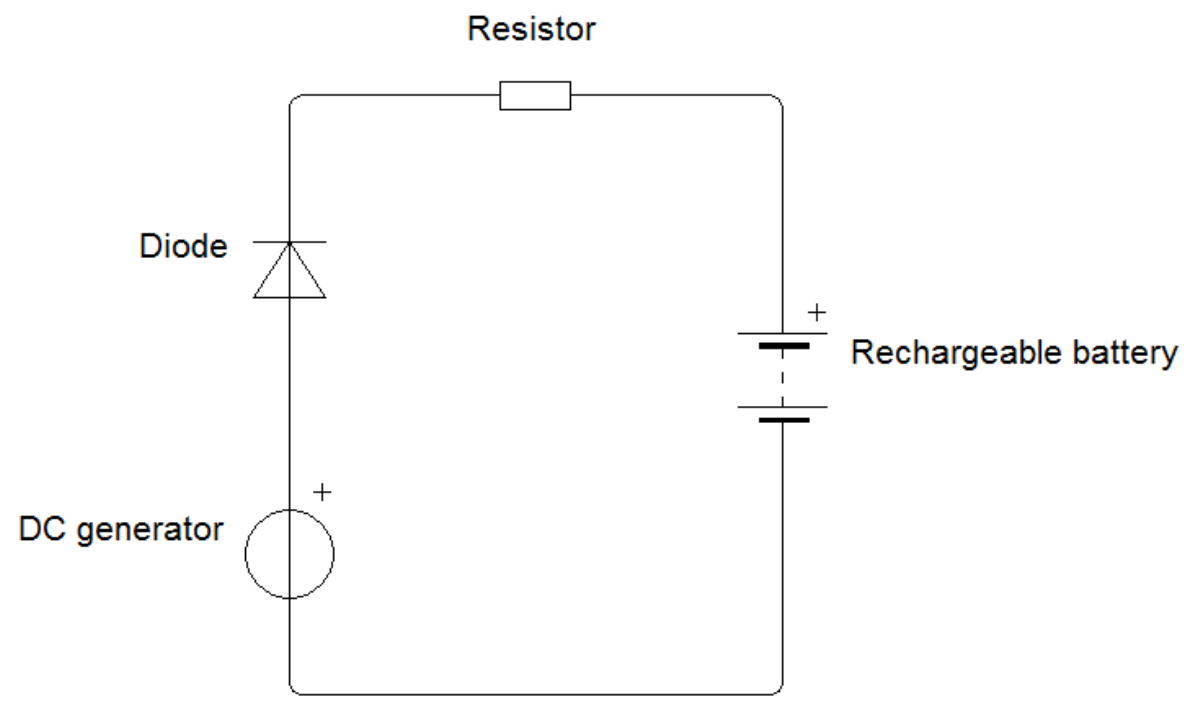

Figure 2. Unregulated charging circuit

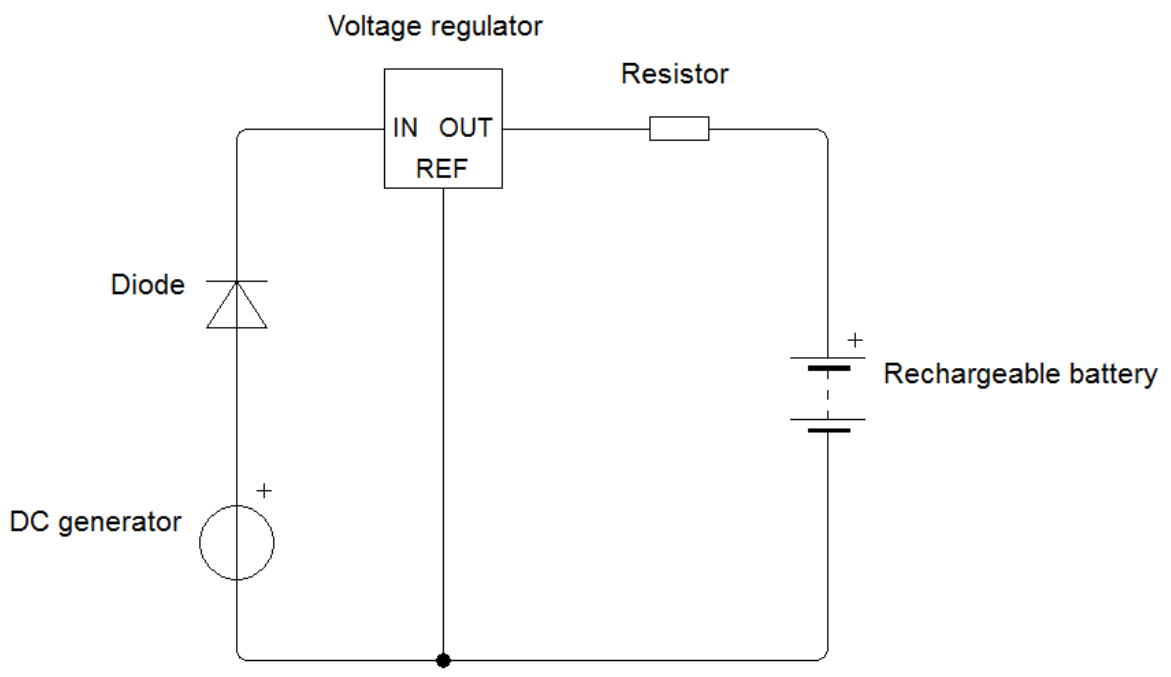

Figure 3. Regulated charging circuit.

\section{Simulation}

The circuits developed were simulated using Livewire Professional Edition software. Livewire software works by constructing schematic circuit into the interface and the values of each component inside the developed circuits are set by the user. The schematic circuit developed can be run to observe the change in the parameters such as voltage, current, resistance and charge.

\section{Experiment}

Three different experiments had been conducted to measure output voltage produced by the generator. The first experiment was to measure the output directly from the generator as shown in Figure 4. The second experiment introduced unregulated charging circuit to 
the first experiment. The third experiment was to replace the unregulated charging circuit to regulated charging circuit. The procedure of the experiments was as follows:

i. Connect dual-shaft motor to the cleaning device, gear system and generator.

ii. Connect multi-meter to the generator.

iii. Turn on the dual-shaft motor.

iv. Record the voltage value display by the multi-meter.

In the second experiment, the unregulated charging circuit (circuit breadboard) must be connected to the circuit, then step 1 until 4 was repeated. In the third experiment, the unregulated charging circuit was replaced with regulated charging circuit, and then step1 1 until 4 was repeated.

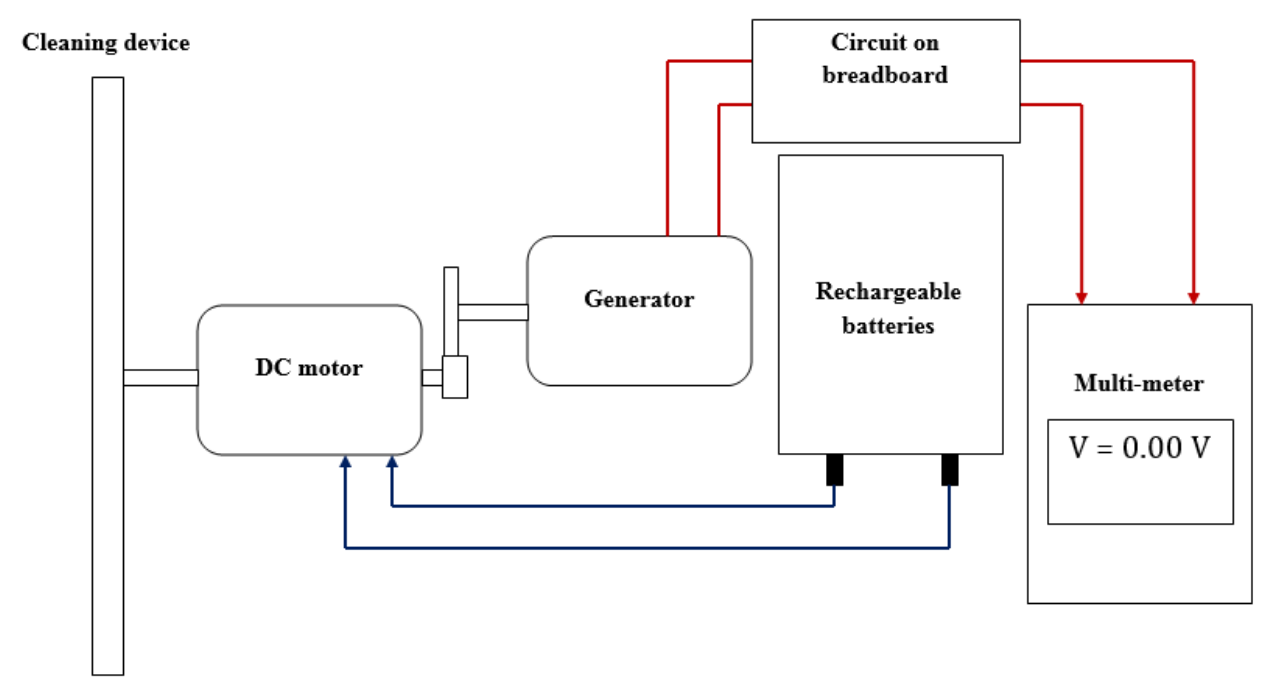

Figure 4. Experimental setup.

\section{RESULTS AND DISCUSSION}

Results of simulations and experiments of the developed circuits are presented in this section followed by discussion. Figures 5 and 6 show the simulation results of the unregulated and regulated circuits accordingly. As shown in these two figures, unregulated charging produces an output voltage of $10.90 \mathrm{~V}$ while regulated charging produces an output voltage of $5.47 \mathrm{~V}$. The unregulated circuit generates higher voltage as compared to regulated circuit. This is due to addition of voltage regulator in the regulated charging circuit that has reduced the voltage produced. Voltage Regulator LM7805 is a linear type - it is easy to use and has good regulation. However, the drawback of the LM7805 is its inefficiency - the efficiency can drop to $50 \%$.

Table 2 shows the summary of results for the experiments. The first experiment measures the voltage from the generator and shows the highest voltage, $7.13 \mathrm{~V}$ as compared to the other two experiments. However, the voltage is inconsistent as the multimeter displayed fluctuating results. The unregulated charging circuit also showed similar inconsistent output voltage with an average output of $6.93 \mathrm{~V}$ which is slightly lower than the first experiment. The third experiment is equipped with a voltage regulator, LM7805 attached to the regulated charging circuit. The voltage regulator enables a consistent output voltage of $5 \mathrm{~V}$ to be produced. 


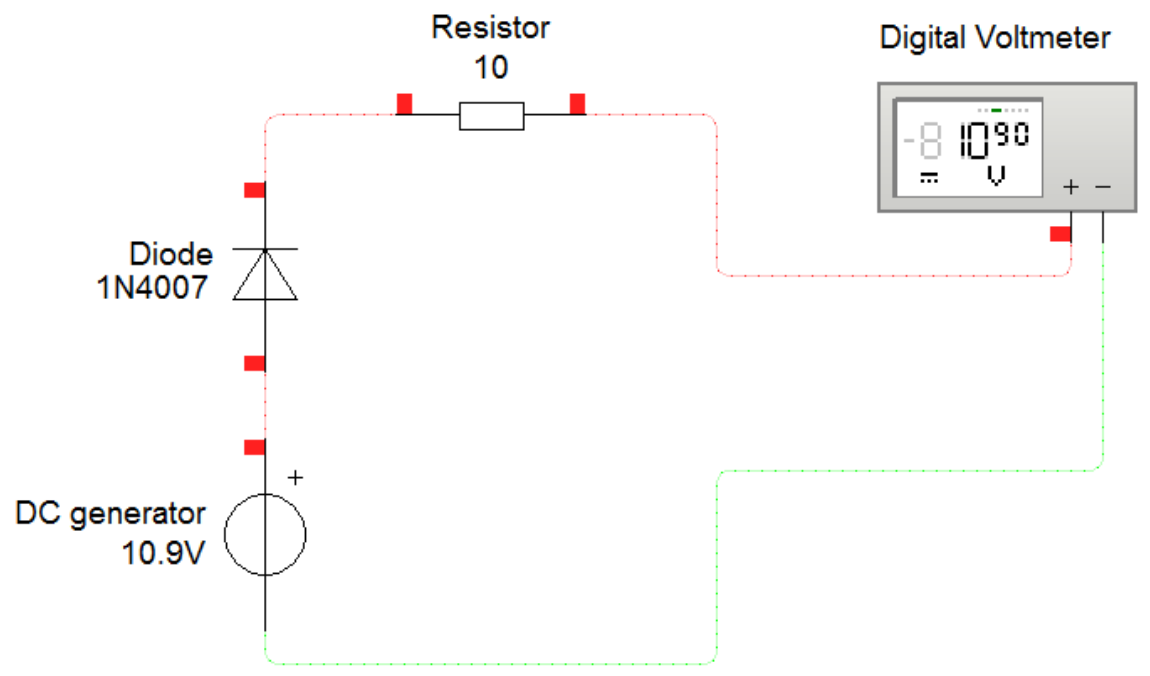

Figure 5. Unregulated charging circuits simulation.

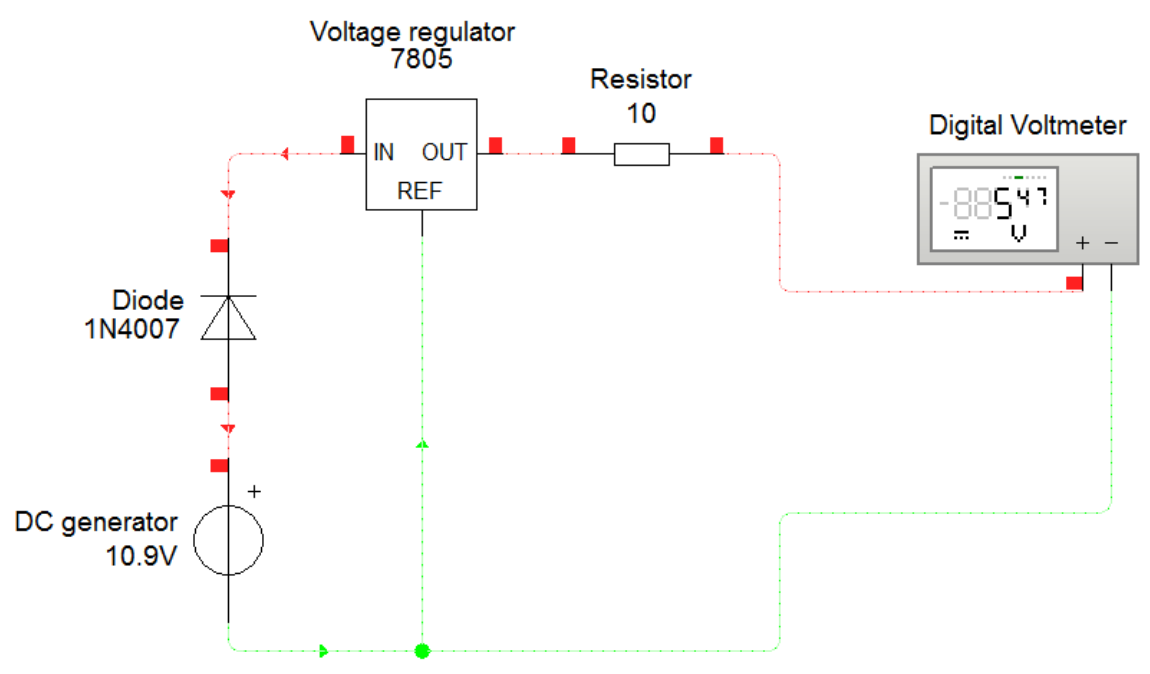

Figure 6. Regulated charging circuit simulation.

Table 2. Results of experiments.

\begin{tabular}{ll}
\hline Experiment & Average output voltage produced \\
\hline 1. Direct from generator & $7.13 \mathrm{~V}$ \\
2. Unregulated charging circuit & $6.93 \mathrm{~V}$ \\
3. Regulated charging circuit & $5.00 \mathrm{~V}$ (constant) \\
\hline
\end{tabular}

Generally, the experimental results showed lower voltages compared to the analytical study in Electronic devices section and simulations. The drop is due to the power loss during the actual transmission process, whereas in analytical and simulation study it is assumed that the power transmission is in an ideal condition. On top of that, the inconsistent voltages produced by the generator was not visible from the simulation results until the experiments were conducted. The experiments have generally confirmed the results of simulations showing the voltage produced by the unregulated charging 
circuit being higher than regulated circuit. Results from the experiments also highlighted the importance of having a voltage regulator in the circuit to get a consistent output voltage. Although the voltage regulator has dropped the initial voltage produced by the generator, it is considered as safer. If the voltage received by the rechargeable battery is excessive, the battery will get overcharged eventually damaging the battery. The unregulated charging circuit is not suitable to be used in power regeneration system for in-pipe robot due to its inconsistent output which could damage the battery if the power is continuously supplied during the charging process. Hence, according to the analytical study, the regulated charging circuit has produced sufficient enough power to recharge the battery of $4.2 \mathrm{~V}$ for micro-controller and other actuators to operate (refer Table 1).

The dual-shaft motor specification speed is $11,500 \mathrm{rpm}$. Equipping the generator has increased the load of the DC motor, thus contributing to $20 \%$ loss as the speed of cleaning device became 9,200 rpm $\left(\oplus_{1}\right)$. As the speed is reduced, the performance of the cleaning device is slightly affected. Therefore, the cleaning device has to improve the cleaning mechanism. Quite likely, the device cannot solely rely on the high rotation speed to clean the pipeline. Alternatively, higher speed motor can be considered too.

In order to minimise the power loss, a mechanical gear system has been introduced to the system. In future, the concept of power board can be applied to boost the generated voltage [6]. At the moment, the generated power is used to supply power to the microcontroller and other actuators. By using a power board and step-up voltage regulator, higher power can be generated and potentially shared with the cleaning device or other additional devices to support the IPR functions.

\section{CONCLUSION}

Electrical energy has successfully been harvested from an IPR cleaning device. This research has applied the Faraday's Law. The rotation of the cleaning device acts as a bicycle dynamo that converts the magnetic flux through a loop into induced current to generate electricity. The correct selection of gear pairs enables perfect match of the rotated shaft to the generator, thus allowing efficient and smooth power transmission. Ohm's Law has successfully been applied to find the value for resistor component for the system. Three different circuits; direct, unregulated and regulated circuits have been developed and simulated. From the experimental result, the best circuit to be used in power regeneration system for IPR application is regulated charging circuit. The circuit produced a consistent $5 \mathrm{~V}$ which can be used to charge up the rechargeable battery of $4.2 \mathrm{~V}$ to ensure a continuous supply of power for the IPR operation.

As a conclusion, the developed system has successfully harvested energy from the rotating motion of the IPR cleaning device enough for the cleaning operation and to move the IPR until its next exit, thus enabling the IPR to extend its longevity and performance as well. The circuits developed for energy harvesting can be applied for IPR and other similar applications that require independent power sources.

\section{ACKNOWLEDGEMENT}

This project is funded by Small Grant Scheme, Universiti Malaysia Sarawak F02(S164)1197/2015(01). The authors also would like to thank the Faculty of Engineering and UNIMAS for their support. 


\section{REFERENCES}

[1] Abidin ASZ, Pauzi MFAM, Sadini MM, et al. Development of Track Wheel for In-pipe Robot Application. Procedia Computer Science 2015; 76: 500-505.

[2] Abidin ASZ, Zaini MH, Pauzi MFAM, et al. Development of Cleaning Device for In-pipe Robot Application. Procedia Computer Science 2015; 76: 506-511.

[3] Malvadkar SB, Parsons EL. Analysis of potential power sources for inspection robots in natural gas transmission pipelines. Topical Report National Energy Technology Laboratory, 2007.

[4] Matiur R, Mamun A, Rabbi MF. Implementation of mechanically powered battery charger. ARPN Journal of Engineering and Applied Sciences 2016; 13: 19141917.

[5] Reddy NRR, Sreekanth Y, Narayana M. Mechanical and Electrical mobile charger. International Journal of Engineering Research and Applications 2013; 3: 17051708.

[6] Parrott C, Dodd T, Groß R. HyMod: A 3-DOF Hybrid Mobile and SelfReconfigurable Modular Robot and its Extensions. In: 13th International Symposium on Distributed Autonomous Robotic Systems. 2016, pp. 401-414.

[7] Onal CD, Chen X, Whitesides GM, et al. Soft mobile robots with on-board chemical pressure generation. In: Christensen, H, Khatib O (ed) Springer Tracts in Advanced Robotics. Springer, 2017, pp. 525-540.

[8] Chen Y, Deng Y, He W. The Design of Photovoltaic Scroll Surface Cleaning Robot. In: 2nd International Conference on Mechatronics and Information Technology. Francis Academic Press, 2017, pp. 439-443.

[9] Bou-Rabee M, Sulaiman S, Choe G, et al. Characteristics of solar energy radiation on typical summer and winter days in Kuwait. International Journal of Automotive and Mechanical Engineering 2015; 12: 2944-2953.

[10] Buchla DM, Floyd TL. Electronics fundamentals circuits, devices and applications (8th ed.). 8th Edition. London: Pearson, 2014.

[11] Budynas RG, Nisbett JK. Shigley's mechanical engineering design (10th ed.). 10th Editi. New York: McGraw Hill Education, 2015.

[12] Kuphaldt TR. Ohm's law- How voltage, current and resistance relate. All About Circuits. Online textbook. Retrieved from https://www.allaboutcircuits.com/ textbook/; 11 Apr, 2017.

[13] Floyd TL. Electronic Devices. 8th ed. Pearson, 2008. Epub ahead of print 2008. DOI: 10.1016/B978-0-8155-1573-9.50007-0.

[14] Texas Instruments. $\mu$ A7800 Series Positive-Voltage Regulators. www.DatasheetCatalog.com, pp. 1-15, revised July, 1999. 